\title{
Research Huawei's Human Resource Management Model by Wireless Network Communication and Association Rule Algorithms
}

\author{
Ming $\mathrm{Li}^{1}$ and Min Zheng $\mathbb{D}^{2}$ \\ ${ }^{1}$ Library, Fujian Institute of Engineering, Fuzhou, 350118 Fujian, China \\ ${ }^{2}$ College of Logistics, Linyi University, Linyi, 276001 Shandong, China
}

Correspondence should be addressed to Min Zheng; zhengmin@lyu.edu.cn

Received 5 August 2021; Revised 7 September 2021; Accepted 22 September 2021; Published 11 October 2021

Academic Editor: Zhihan Lv

Copyright (c) 2021 Ming Li and Min Zheng. This is an open access article distributed under the Creative Commons Attribution License, which permits unrestricted use, distribution, and reproduction in any medium, provided the original work is properly cited.

\begin{abstract}
The pros and cons of the human resource management model are related to the size of an enterprise's future development space. In the current era of increasingly fierce competition among enterprises, it is becoming more and more important to study the latest types of human resource management models and apply them to themselves. As a great management enterprise, it is necessary for Huawei to study its human resource management model. This article is based on the wireless network communication method and association rule algorithm applied to the research of Huawei's human resource management model. Through interviews with Huawei employees, we found that $18 \%$ of people are very satisfied with the company, $27 \%$ are relatively satisfied with the company, and $40 \%$ are satisfied with the company now. Therefore, most employees are satisfied with the company now. $85 \%$ of people are satisfied with the company's current situation. The results show that Huawei's excellent human resource management model has made employees more satisfied with the current company's current situation. There are great opportunities for employees to continue to learn and progress in the company.
\end{abstract}

\section{Introduction}

Our country is in a period of significant economic transformation and deepening reform. In the current process of gradual upgrading of the industry and continuous deepening of supply-side reforms, this is a historical issue. It has become particularly necessary to study the human resource management model of Chinese enterprises. Human resource management is a stage of human management. This stage is marked by the management of human resources as resources. However, when studying its development process, human resource management, and other personnel management and interpersonal management before the concept is put forward are inseparable [1]. From a broad perspective, whether people define human resources as resources, human resources as one of the four major resources of society, human resources, economy, material, and information, always exist [2]. As my country's greatest startup company,
Huawei's human resource management model is extremely successful, so we use wireless network communication and association rule algorithms to study Huawei's human resource management model.

A large number of researches on human resource management have been conducted at home and abroad, and many experts have provided a variety of human resource management models. Ludiya et al. of Harvard Business School took the lead in conducting the first human resource model research and published "Human Management." The focus is on how to enable the company's CEO to better manage the problems they face when managing a company with a large number of employees [3]. Wei and Jin also made relevant suggestions in a paper published in the journal "Management Research." Geist model emphasizes the difference between human resource management and traditional labor management, compares the difference between modern human resource management and traditional human 
resource management, develops a suitable human resource management model, and explains how to construct it [4]. Gao and Sun's "Cross-Cultural Model of Human Resource Management and Its Application in Sino-foreign Consortiums" focuses on the collaborative management model of cultural management model, which is based on the analysis of human resources of multinational companies [5]. The "Human Resource Management Model Model" proposed by Ghasemi et al. is based on the company's vision, strategic goals, and cultural values, and uses the four key links of selection, training, recruitment, and retention as the framework to strengthen the company's strength and skills [6]. In his article, Mendy and Rahman proposed a general algorithm for the standard association rule algorithm based on the MapReduce-PFP framework [7]. Li et al. detect the data output rate. According to the level of data output, the organization rules can be divided into single-level organization rules and multilevel organization rules, according to the variable types considered in the association rule algorithm [8]. Dahlan and Fatmawada can be divided into Boolean association rules and multivalue association rules. In the association of values, you can use the number symbol and the grade symbol to distinguish [9].

Previous studies have proposed many human resource models, but the research on the application of wireless network communication and association rule algorithms to human resource management models is not sufficient. Innovation of this paper is as follows: first, the wireless network communication and association rule algorithms to study the management of the model; second, careful study of current practices and emerging concepts of human resource management. It discusses the new trend of the transformation of human resources and improvement in the future development of China's enterprises. This makes the paper has a strong practical value and specific perspective. Of course, it is inevitable there will be some shortcomings, we combine the content of the article has been clarified in the back.

\section{Research Method of Wireless Network Communication and Association Rule Algorithm on Human Resource Management Model}

2.1. Overview of the Development and Status Quo of Wireless Network Communications. With the increase in the number of mobile users and the improvement of people's material living standards, the demand for wireless communication network technology is also increasing. The impact of wireless technology on mankind is undeniable. Since the frequency band of wireless network communication technology does not require any telecommunications operating license worldwide, WLAN wireless equipment provides a wireless air interface that can be used worldwide with extremely low cost and extremely high data bandwidth. Users can quickly browse web pages within the Wi-Fi coverage area and answer and make calls anytime, anywhere. And some other broadband data applications based on WLAN, such as streaming media, online games, and other functions, are more worthy of users' expectation. Today, about 10,000 people become new wireless users every day, and the number of wireless users worldwide has now exceeded 100 million [10]. With the rapid development of computer technology and network technology, the network usage of all social strata is increasing day by day. Wired network has an absolute reputation and market share in the market due to its high transmission speed, numerous brands and numbers of products, and fast technological development. Compared with wired networks, wireless networks have reliable communication, low cost, and flexibility. The wireless network can effectively perceive changes in the external environment, further understand and learn more deeply, and efficiently adjust and configure relevant resources within the communication network to cater to the changes in the external environment. By making full use of the wireless cognitive network technology, the conflict between the increasing demand for spectrum and the limited spectrum resources can be resolved, the problem of scarcity of spectrum resources can be effectively resolved, and the efficiency of spectrum application can be reasonably improved. Compared with the wired network, the main feature of the wireless network is that it completely eliminates the limitations of the wired network, realizes the wireless transmission of information, and enables people to use the network more freely. At the same time, network operators are also very convenient to operate. First of all, line construction costs are reduced, running time is shortened, and cost returns and profit production are relatively fast. These advantages include improved wireless information transmission management for administrators and greater flexibility for users who do not have space constraints on the network. The first-generation mobile communication system is an analog mobile communication system that uses analog transmission to provide voice services, including AMPS in the United States, TACS in the United Kingdom, NMT in Scandinavia, and NTT in Japan [11]. The second mobile telecommunications system that represents the global CMS and IS-95 system is designed for low-speed voice services. The second generation is transferred to the third generation, which increases the ability to transmit packet data services, improves the success rate of continuous transmission, and allows mobile device users to access more wireless data in addition to voice services [12]. The implementation of the third phase of the mobile communication system is mainly carried out within the ETSI framework, and SGM is responsible. The RACE project created the basic research of the third mobile communication system. CDMA-based CDMA systems mainly include WCDMA and TD-SCDMA systems that use direct sequencing, and cdma2000 systems that use multiple management methods, which can provide mobile users with services such as the deployment of voice, data, video, web browsing, and other services, support mail packet data rate up to $2 \mathrm{Mbps}$ [13]. UMTS is one of the main standards of the first-generation mobile communication system based on the evolution of the GSM network. The hierarchical bearer UMTS-QoS structure is shown in Figure 1: 


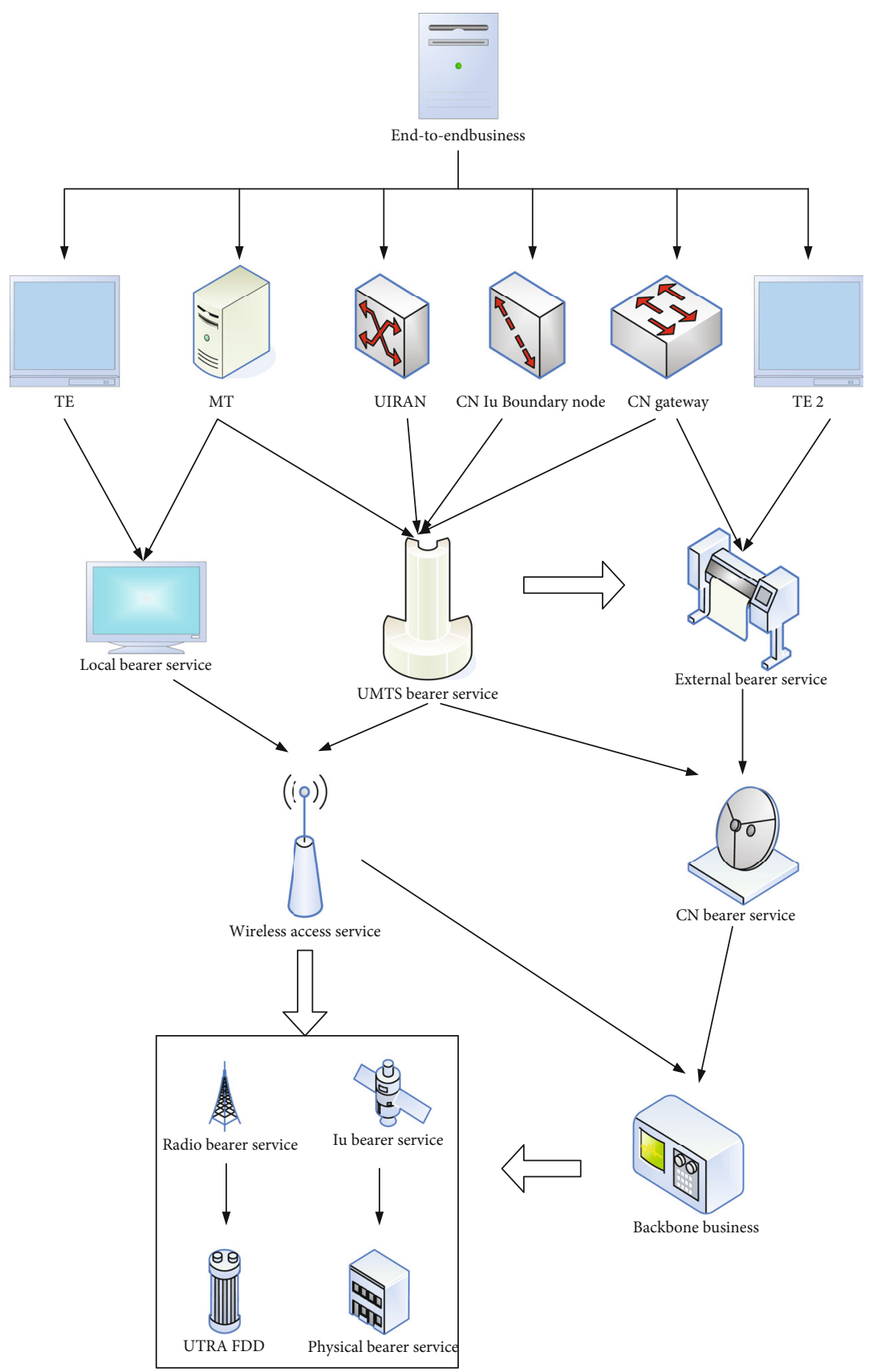

FIgURe 1: UMTS-QoS structure diagram.

Operator service describes how a specific network provides QoS, which is defined together with signature protocol, transmission plane, and QoS management functions [14]. One of the biggest benefits of the third-generation mobile communication technology is that it gives operators the freedom to manage QoS, and the quality of service (QoS) is evolving from a general concept to a strictly quantitatively defined network management mechanism. The QoS hierarchical structure and management function implementation gives a UMTS QoS guarantee architecture. When affected by multiple networks, end-to-end management services can be divided into three directions: TE/MT local bearer services provided between terminal equipment and mobile terminals, and external bearer services provided between core gateways and external TEs.

2.2. Research Status of Association Rule Algorithm. Association rule algorithm belongs to a rule-based learning algorithm. Association algorithms are an important class of algorithms in data mining. In 1993, Agrawal et al. first proposed the problem of mining association rules between item sets in customer transaction data, and the core of which is a recursive algorithm based on the idea of two-stage frequent sets. The association rules are classified as single-dimensional, single-layer, and Boolean association rules, and the typical algorithm is the Apriori algorithm. This algorithm 
can use some metrics to mine the association rules that exist in the database [15]. People filter out some highly relevant items by the number of items in the data set. Goods with strong relevance must meet certain requirements. One is to meet the minimum quantity of goods in the total transaction. This minimum quantity is usually measured by the minimum support degree [16]. The other is that the number of two highly correlated items that appear in a transaction at the same time must reach a certain proportion in all transactions. This proportion is usually measured by the minimum support and the minimum confidence, as shown in Table 1.

The Apriori algorithm divides the process of discovering association rules into two steps: the first step is to iteratively retrieve all frequent itemsets in the transaction database 1, that is, the item sets whose support is not lower than the threshold set by the user; the second step is the frequent itemsets are used to construct rules that satisfy the user's minimum trust. Among them, mining or identifying all frequent itemsets is the core of the algorithm, which accounts for most of the entire calculation. The support degree represents the frequency of the item set in the entire transaction database. Assuming that the transaction database contains $T$ pieces of data, the calculation formula for the support degree is

$$
\operatorname{Sup}(x)=\frac{\operatorname{Sum}(x)}{T}
$$

Confidence degree indicates how often a specific rule appears in the transaction database. For the confidence level, its value represents the proportion of the total transactions that also contain $N$ under the condition of including $M$ [17]. Assuming that there are $x$ transactions in the transaction database, the calculation formula for confidence is

$$
\operatorname{Conf}(M \Rightarrow N)=\frac{\operatorname{Sup}(M \cup N)}{\operatorname{Sup}(M)}
$$

Taking the above transaction database as an example, the confidence level of $\{$ beer, diapers $\}$ is $0.2 / 0.2=1$. The specific meaning of this formula is that as long as the transaction that contains beer, it must contain diapers. In this way, a minimum confidence value can be set on this basis. Apriori algorithm is the most classic algorithm for mining association rules [18]. Then introduce the principle of Apriori algorithm, correlated with transaction data between two pairs of two in a positive correlation, the correlation between them is very strong. The Apriori algorithm is widely used in commerce and in consumer market price analysis. It can quickly find the price relationship between various products and their influence. Through data mining, marketers can target target customers and use personal stock prices, the latest information, special marketing activities, or some other special information methods, thereby greatly reducing advertising budgets and increasing revenue. Hadoop is an open source software platform under Apache. Hadoop is a software framework that can perform distributed processing on large amounts of data. Hadoop performs data processing in a reliable, efficient, and scalable way. Hadoop is reliable
TABLE 1: Transaction data table.

\begin{tabular}{lccccc}
\hline Affairs & Milk & Bread & Butter & Beer & Diapers \\
\hline 1 & 1 & 1 & 1 & 1 & 0 \\
2 & 0 & 1 & 0 & 0 & 0 \\
3 & 0 & 0 & 1 & 1 & 1 \\
4 & 1 & 0 & 0 & 0 & 0 \\
5 & 0 & 1 & 1 & 0 & 1 \\
\hline
\end{tabular}

because it assumes that computing elements and storage will fail, so it maintains multiple copies of working data to ensure that it can redistribute processing for failed nodes. It is committed to using server clusters and has powerful distributed storage and computing capabilities. It can design its own business logic for different application scenarios to perform distributed processing of massive data [19]. When the size of a data set exceeds the storage capacity of an independent physical computer, it is necessary to partition it and store it on several separate computers. The file system stored across multiple computers in the management network becomes the distributed file system (distributed file system). This system is built on the network and will inevitably introduce the complexity of network programming. Therefore, the distributed file system is more complicated than the ordinary disk file system. HDFS is a distributed file storage system and provides a unified abstract directory tree to the client. As a distributed file system, HDFS is designed to handle large files. Using abstract blocks will bring many benefits. One advantage is that it can store arbitrarily large files without being limited by the disk size of any single node in the network. The client accesses files through paths. The working mechanism of HDFS writing data is shown in Figure 2.

The current association rule algorithm needs to set the value of the interest measure, and how to set it depends excessively on expert knowledge and complicated adjustment process. In the support setting, too large support will lead to too few frequent items, and too low support will lead to too many frequent items, which is not conducive to analysis [20]. We can solve the above problems effectively through a Markov logic network framework model of association rules. A Markov network is a joint distribution model of random variables $M=M 1, M 2 \cdots, M 3$. It is composed of an undirected graph and a set of potential functions $\Phi$. Each random variable is a node on the graph, that is, each clique. The node can be regarded as each item in the item set. The joint probability formula of the Markov network of each group in the figure is

$$
P(M=m) \frac{1}{z} \prod \phi(x(k)) .
$$

In formula (3), $x(k)$ represents the state of a random variable, and $Z$ is the partition function, which can be obtained:

$$
Z=\sum_{x} \prod \phi k x_{(k)}
$$

All the eigenvalues of the potential function of each 


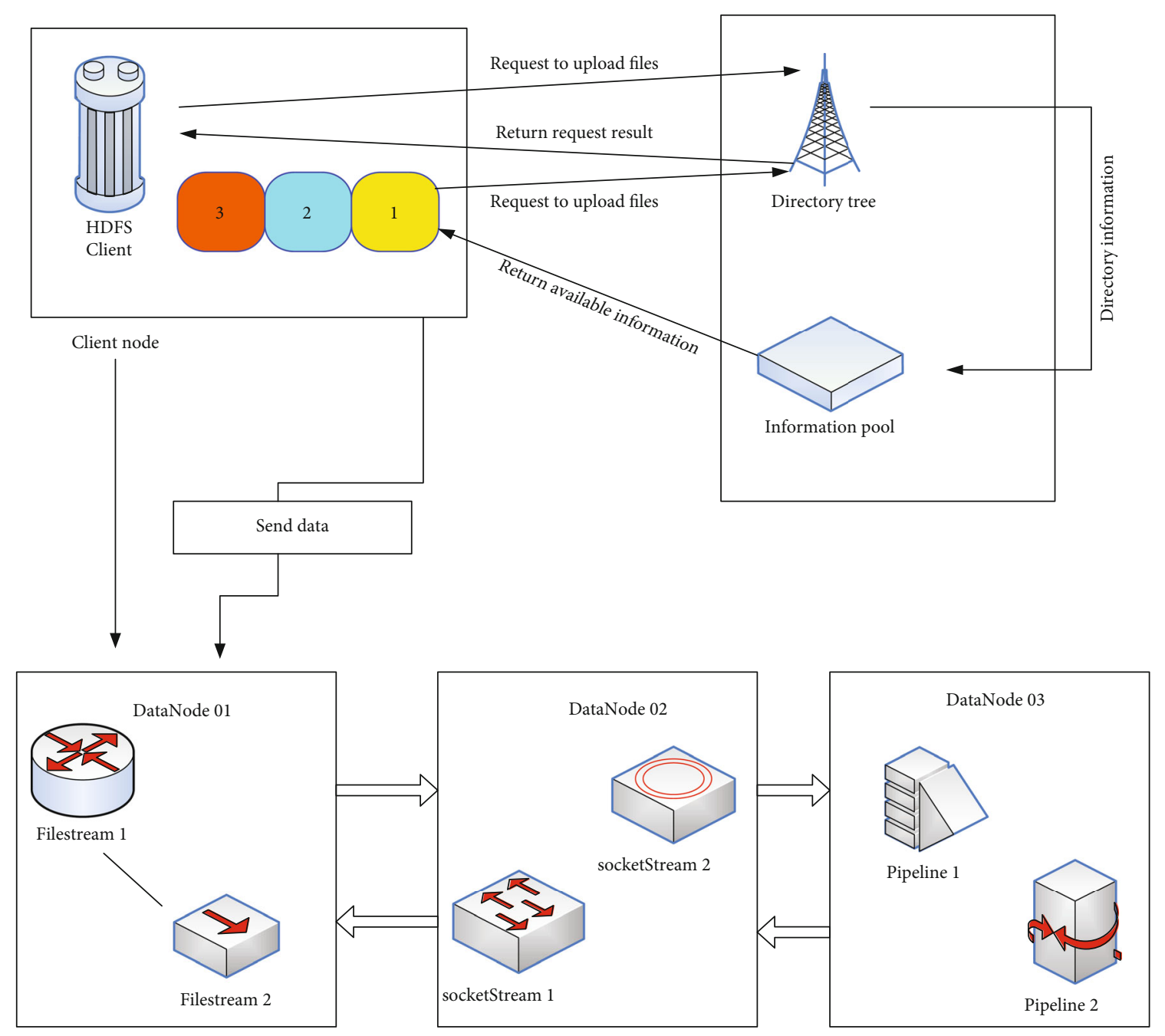

FIGURE 2: HDFS file writing mechanism.

clique in formula (3) are weighted and then summed and then exponentiated, and formula (5) can be obtained:

$$
P(M=m)=\frac{1}{z} \exp \left(\sum w f(x)\right)
$$

The characteristic function can represent any real function of the state. Formula (5) is the most direct representation of the potential, in which each possible state of each clique has a corresponding eigenvalue $f(x)$, and its weight is $w$, the formula related to the power of the number of cliques. According to formulas (3)-(5), the probability distribution of the logical network can be obtained as follows:

$$
P(M=m)=\frac{1}{z} \exp \left(\sum w n(x)\right)=\frac{1}{z} \prod \phi x_{i} .
$$

If the rule related to $i$-th elementary atom has $n(x)$ true elementary shapes in the data $X$, the derivative of the log probability likelihood function of equation (6) with respect to the weight $w$ is

$$
\frac{\partial}{\partial w} \log P(X=x)=n(x)-\sum P\left(X=x^{\prime}\right) n(x)
$$

According to formula (7), the weight can be learned, and the Markov logic network framework model of the association rule can be mined by using the random gradient method. Each transaction is a possible world assigned by the network model. It contains not only the information of a single node but also the relationship between nodes. $X=$ $(X 1, \cdots X i, \cdots X n)$, the value of each $x$ is $\{0,1\}, \chi=(\chi 1, \cdots, \chi$ $i, \cdots \chi n)$ is that each transaction is represented as an $n$ -dimensional 0,1 vector. $\chi$ is the set of vector representations of all transactions in a database. The network model is given in the following equation:

$$
P(X=x)=\frac{1}{z} e \sum_{i=1} \alpha_{i} * x_{i}+\sum x_{j} * x_{k}
$$

Among them, the value of $i, j$, and $k$ ranges from 1 to $n$, 
and $n$ is the number of items or attributes in the entire database. In addition, the explanation equations of $a_{i} * x_{i}$ and $x_{j} * x_{k}$ are shown in the following formulas:

$$
\begin{aligned}
& a_{i} * x_{i}=1 \text { if } x_{i}, x_{k} \text { are both } 1,0 \text { otherwise, } \\
& f\left(x_{j} * x_{k}\right)=i \text { if } x_{j}+x_{k}=1,0 \text { otherwise. }
\end{aligned}
$$

From equations (9) and (10), we can see

$$
Z=\sum e^{\sum a i^{*} x i} \sum w f\left(x_{j}, x_{k}\right)+\sum w^{*} f\left(x_{j}, x_{k}\right) .
$$

This article uses the quasilikelihood function to change the original $P(X=x)$ to eliminate $Z$, and we can get the following formula:

$$
P(X=x)=\prod \frac{e^{a x+\sum w f\left(x_{i}, x_{k}\right)}}{e^{a x+\sum w f\left(1, x_{k}\right)}+e^{a i^{*} 0+\sum w f\left(0, x_{k}\right)}} .
$$

By scanning the sample data to learn the parameters of the Markov logic network framework model of the association rules, the sample data is large, the stochastic gradient descent method is an effective way to solve the parameter learning under the large sample data, and the training speed is fast [21]. The following is the algorithm of stochastic gradient solving based on the Markov logic network framework model of association rules, where the update formula is as follows:

$$
\begin{gathered}
a_{i}^{(s+1)}=\alpha+\gamma \nabla \log (p(X-x)), \\
w_{i}^{(s+1)}=w+\gamma \nabla w+\log (p(X=x)), \\
w_{i}^{s}=w^{s}+\gamma \nabla w-\log (p(X=x)) .
\end{gathered}
$$

By solving the Markov logic network framework model of the association rules, and get the parameter update formula in the stochastic gradient descent method, I can establish the Markov logic network framework model algorithm of the stochastic gradient descent method to solve the association rules.

\subsection{Concept of Human Resource Management Model.} Human resource management refers to the effective use of relevant human resources inside and outside the organization through recruitment, selection, training, compensation, and other management forms under the guidance of economics and humanistic thinking, to meet the needs of the organization's current and future development, and to ensure that the organization's goals are achieved and achieved. The general term for a series of activities to maximize member development [22], it is the whole process of predicting the organization's human resource needs and making a human demand plan, recruiting and selecting personnel and organizing effectively, evaluating performance and paying compensation and providing effective incentives, and combining the needs of organizations and individuals for effective development in order to achieve optimal organizational performance [23]. For the exact concept of the human resource management model, we have not yet found a clear and clear explanation, but we can summarize three mainstream interpretations based on various documents published at home and abroad: the first interpretation believes that the human resource management model is human resource management system, and foreign human resource management models mainly include Harvard model, Geist model, and Storey model [24]. The second explanation is that the human resource management model is a classification based on the evaluation of different organizations on the relevant variables of the human resource management model and the classification of different scores. The foreign human resource management models mainly include traditional types of cost reduction models and modern models. There are two types of employee commitment models; domestic human resource management models mainly include a control model that is directed toward reducing costs and a commitment model that is directed toward improving employee commitments [25]. The third interpretation is that the human resource management model is a human resource management practice system based on management concepts. According to the practical effect, it is divided into the best and the nonoptimal systems. To sum up, the human resource management model is a dynamic, holistic, and purposeful management method. It is the long-term practical work of human resource management for companies and enterprises to integrate resources and maximize their overall benefits. Goals refine the various practical activities and overall systems of human resource management, comprehensively summarize and highly analyze the goals, permissions, levels, content, and methods of the company, and enterprise human resource management, so as to achieve the goal of giving full play to the human resource management functions. At the same time, human resource management activities or module combinations that can be generally observed and recognized by companies and business participants can usually be divided into different types according to different focuses.

\section{Analysis Wireless Network Communication and Association Rule Algorithm on Human Resource Management Model}

\subsection{Research Wireless Cellular Communication Network and} Resource Management Algorithm. There are two ways to simulate the wireless cellular communication system. One is event-driven. Every event that occurs in the model arrives at some point. The second is the discrete-time simulation method. For the entire simulated system, only its "snapshots" at evenly spaced time points are studied, that is, sampling at uniform time intervals. Wireless resource management mainly includes several aspects such as bandwidth allocation scheme, call admission control algorithm, wireless packet scheduling algorithm, power control algorithm, and load control $[12,13]$. The basic model of the wireless resource management algorithm located in the base station is shown in Figure 3. 


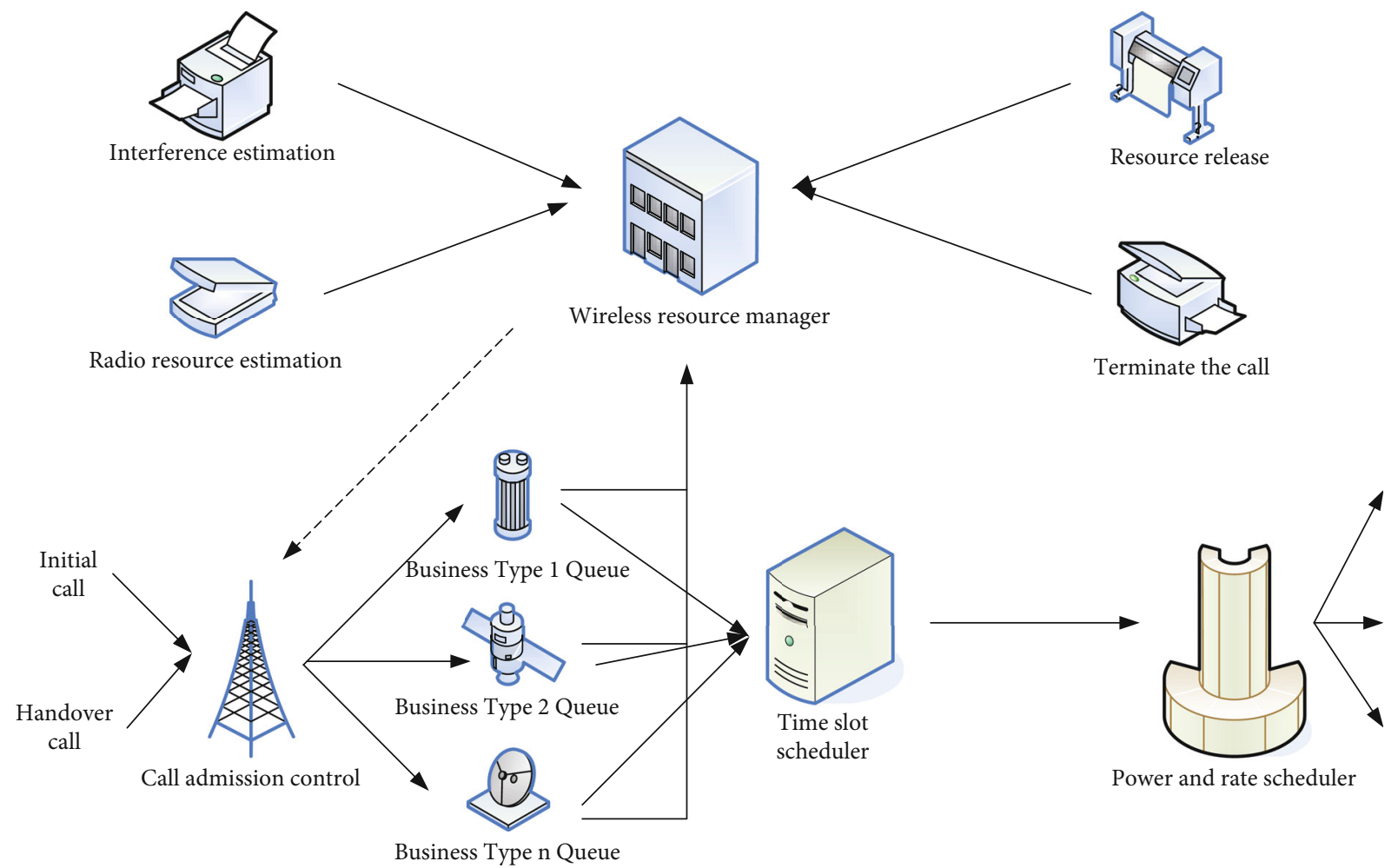

FIgURE 3: The basic model of the wireless resource management algorithm in the base station.

To ensure the accuracy of the above analysis, computer simulation methods can be used for verification. All resource management algorithms and wireless network analysis and simulation are integrated into the wireless mobile network simulation platform [14]. The simulation platform is divided into the initialization part of the overall system structure and the two-layer main loop part. The two-layer main body loop is divided into the outer main body loop and the inner main body loop. The specific flow chart is shown in Figure 4.

The arrival of new calls is assumed to be distributed with Poisson, the average arrival rate is how many calls per second per cell, and the call is the arrival rate of new calls generated anywhere in the cell with an equal probability. In each mobility situation, the value of the new call arrival rate is determined by a random experiment that obeys the binomial distribution law to approximate the distribution. Note that at the beginning of the simulation of each mobility situation, this article generates the maximum acceptable number of users in the system, so that the performance of the entire system can be studied under heavy load conditions. The comparison of the arrival rates of new calls and handover calls shown in Figure 5 shows.

From Figure 5(a), it can be seen that the average value of the arrival rate of new calls is 1.6321 calls per cell in each sample ( 3 seconds), which is equal to the service intensity of 64.123 Erlangs (the average number of holding time for a given call is 120 seconds $=2$ minutes). It can be seen from Figure 5(b) that an explanation of the probability of forced interruption of the call should be necessary. The parameter is the probability that an ongoing call will be forcibly terminated before the connection ends due to signal degradation.
This parameter indicates the proportion of the planned coverage area relative to the actual coverage area. At the same time, it is also related to the probability of successful communication. In the same sense, the comparison chart of forced call interruption probability and handover call interruption probability is shown in Figure 6.

It can be seen from Figure 6(a) that the outage probability is limited to between 0.2 and 0.4 , which is acceptable to the subscribers of the system under appropriate circumstances. However, the increase in mobility also has a slight impact on the probability of forced call interruption due to high mobility, which means a large change in Rayleigh fading and fast fading. It can be seen from Figure 6(b) that when the average speed is between $10 \mathrm{mps}$ and $20 \mathrm{mps}$, the average speed is between $10 \mathrm{mps}$ and $20 \mathrm{mps}$. Between the sexes, the overall trend is rising, but the probability of interruption will oscillate up and down very severely. Finally, when the mobility is very high to high mobility, that is, when it exceeds $20 \mathrm{mps}$, the probability of interruption will pass through slightly increased and gradually maintained to a stable state, and the cost is lower BUR.

\subsection{Analysis of Huawei's Human Resource Management} Model. Huawei Technologies Co., Ltd., established in 1987, is the world's leading provider of information and communication technology (ICT) solutions. Cloud computing and other fields have built up the advantages of end-to-end solutions to build a better fully connected world. Analyzing and researching the best practice cases of Huawei's HR model can provide in-depth enlightenment and direction guidance for Chinese companies to implement the transformation and 


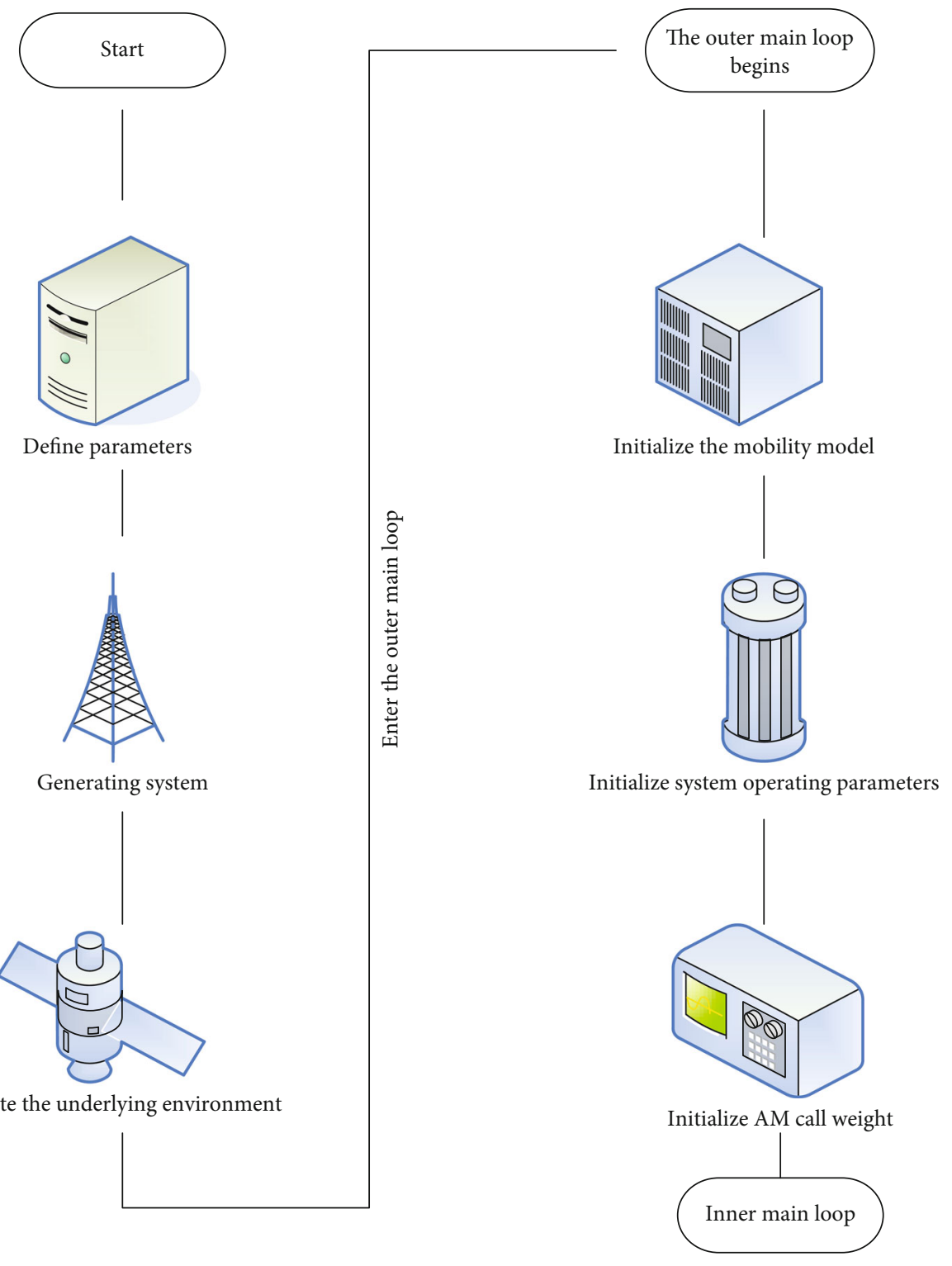

FIgURE 4: The flow chart of the system's overall structure initialization and outer main body loop.

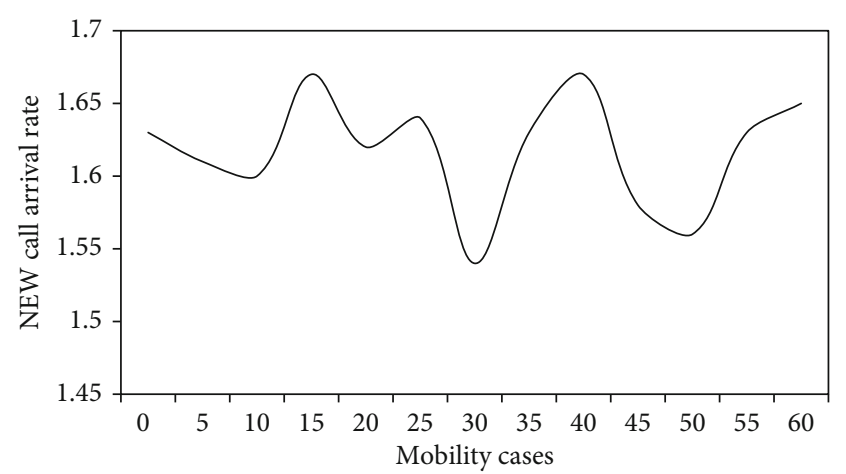

(a)

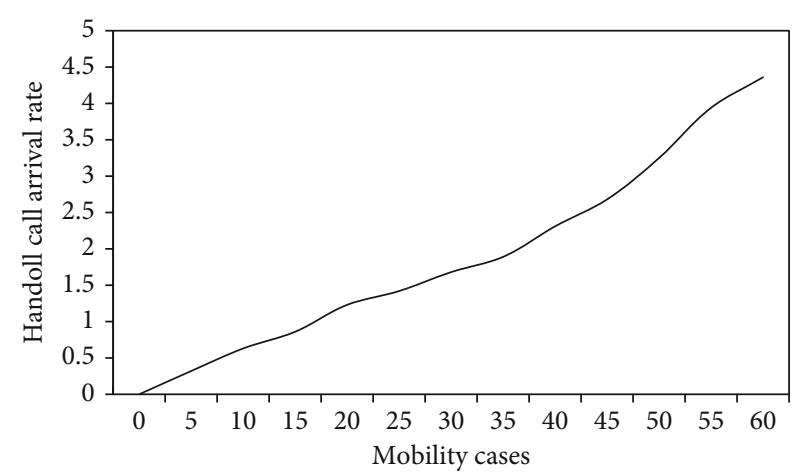

(b)

FIgURE 5: Comparison of the arrival rate of new calls and handover calls. 


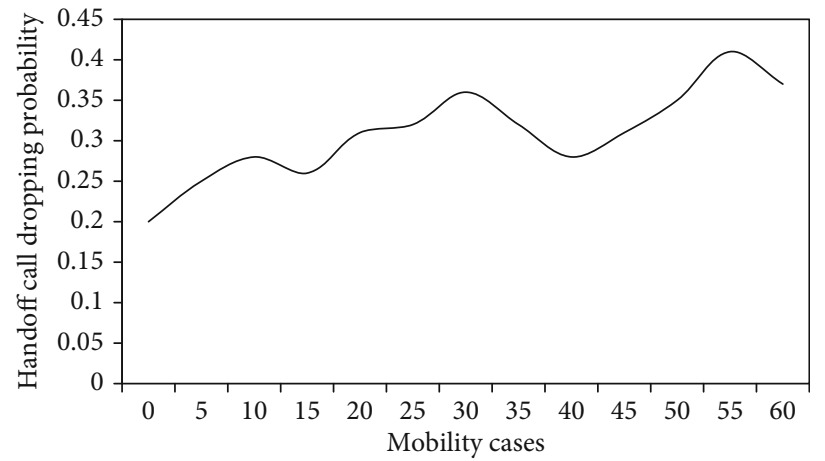

(a)

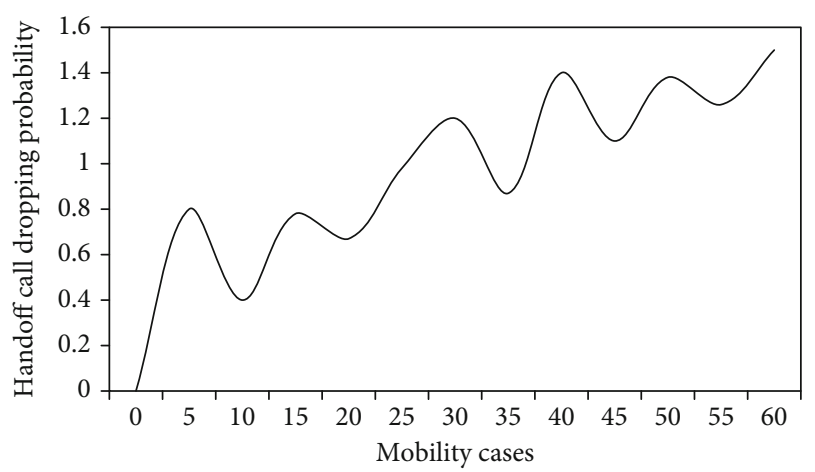

(b)

FIGURE 6: Comparison of forced call interruption probability and handover call interruption probability.

upgrading of human resource management. We provide guidance to Huawei's personnel chiefs, supervisors, managers, and other human resources management. A total of 20 experts conducted interviews, and they were asked to score the indicators designed by the questionnaire. The data characteristics of the interview results used the median method and the average method to calculate the indicator values of the experts. After scoring by experts, the results shown in Table 2 are obtained.

It can be seen from Table 2 that the weights of various indicators in the overall indicators are relatively balanced. Among them, position and company strategy have the highest weights, accounting for $35 \%$ and $30 \%$, respectively, and the lowest weighting is equity incentives. Equity incentives are mainly to give employees part of the shareholders' rights and interests through conditions, so that they have a sense of ownership, thereby forming a community of interests with the company, promoting the common growth of the company and employees, and helping the company to achieve the long-term goal of stable development. In the job segmentation, job matchability accounted for the highest proportion, reaching $20 \%$, and job rationality accounted for $10 \%$. In the strategy, the most important factor was the employment plan, which accounted for $15 \%$, and the lowest segmentation accounted for, respectively, the rationality and fairness of equity incentives, as well as the level of position and professionalism of performance, accounting for $5 \%$. The statistics of Huawei employees' views on the status quo of the company's resource management model and their satisfaction with Huawei's human resources strategic planning are shown in Figure 7.

It can be seen from Figure 7 (a) that $18 \%$ of people are very satisfied with the company, $27 \%$ are satisfied with the company, $40 \%$ of employees are satisfied with the company now, so most employees are satisfied with the company now, and $85 \%$ are satisfied with the company. The status quo, Figure 7(b), shows that the overall satisfaction with the company's human resource planning is only $59 \%, 31 \%$ of employees are dissatisfied, and $10 \%$ are very dissatisfied. According to the interviews, Huawei's human resources management is relatively reasonable. People are quite satisfied with the current Huawei promotion system and salary package and believe that the company has a competitive
TABLE 2: Interview results of reasonable use of reference values for indicators.

\begin{tabular}{|c|c|c|c|}
\hline $\begin{array}{l}\text { First level } \\
\text { indicator }\end{array}$ & $\begin{array}{l}\text { Expert weight } \\
\text { score }\end{array}$ & $\begin{array}{l}\text { Secondary } \\
\text { indicators }\end{array}$ & $\begin{array}{c}\text { Expert weight } \\
\text { score }\end{array}$ \\
\hline \multirow{3}{*}{ Strategy } & \multirow{3}{*}{30} & $\begin{array}{l}\text { Strategic } \\
\text { planning }\end{array}$ & 10 \\
\hline & & $\begin{array}{l}\text { Management } \\
\text { goals }\end{array}$ & 5 \\
\hline & & $\begin{array}{l}\text { Employment } \\
\text { plan }\end{array}$ & 15 \\
\hline \multirow{3}{*}{ Position } & \multirow{3}{*}{35} & Job match & 20 \\
\hline & & Job rationality & 10 \\
\hline & & Job hierarchy & 5 \\
\hline \multirow{3}{*}{ Performance } & \multirow{3}{*}{25} & Rationality & 10 \\
\hline & & Professional & 5 \\
\hline & & Transparency & 10 \\
\hline \multirow{2}{*}{$\begin{array}{l}\text { Equity } \\
\text { incentive }\end{array}$} & \multirow{2}{*}{10} & Rationality & 5 \\
\hline & & Fairness & 5 \\
\hline
\end{tabular}

advantage. However, it can be seen from this that Huawei's human resource management lacks the unity and coordination with Huawei's strategy. In addition, Huawei's current development prospects are limited by sanctions, and the age of senior engineers is seriously imbalanced, which has led to some problems. Old employees cannot retire in time, new employees cannot win promotion opportunities, and so on. The rationality of the design of the evaluation indicators for human resources and the satisfaction of the fairness of the evaluation results of Huawei employees are shown in Figure 8.

As shown in Figure 8(a), most employees are dissatisfied with the rationality of Huawei's current evaluation index design. $51 \%$ of employees believe that the current evaluation index design is unreasonable and only $25 \%$ feel reasonable about it. Employees believe that Huawei's current employee job design lacks rationality, and Huawei should strengthen Huawei's human resources job management from the perspective of improving the rationality of job design. It can be seen from Figure 8(b) that 10\% of employees are very satisfied with the fairness and transparency of Huawei's assessment results, $33 \%$ are more satisfied, $36 \%$ are satisfied, and 


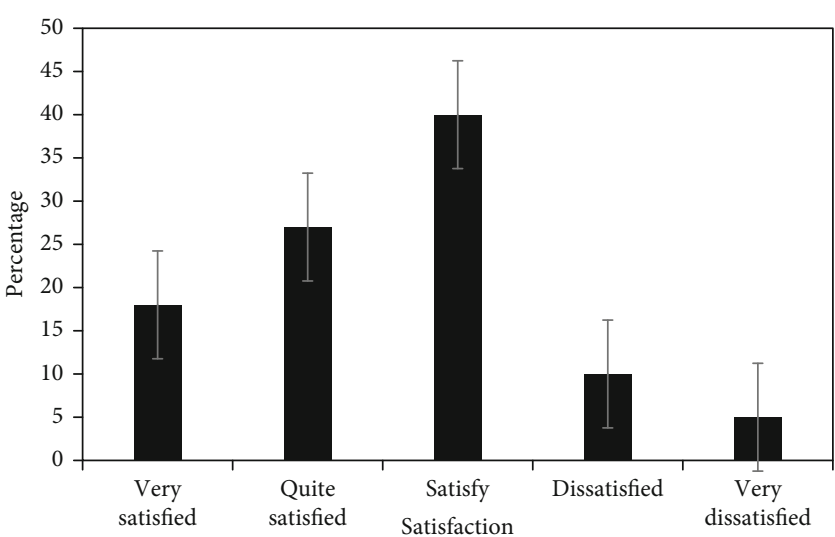

(a)

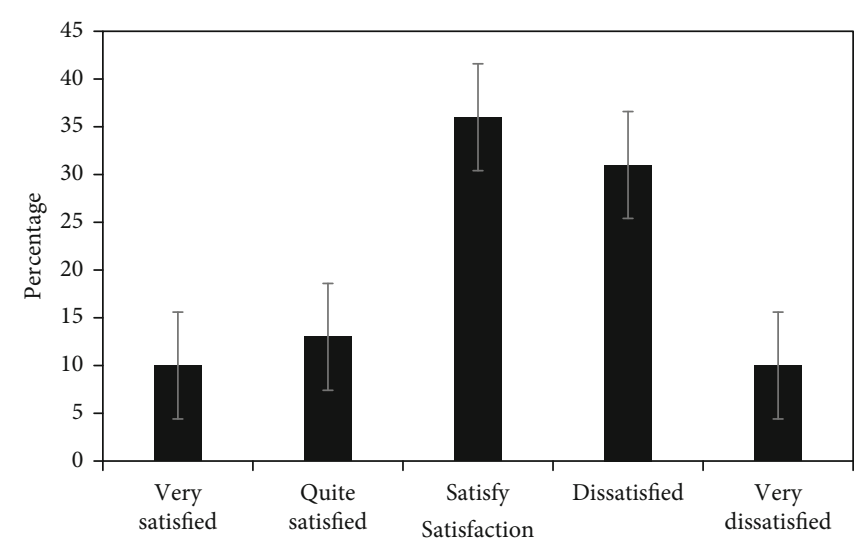

(b)

FIgURe 7: Huawei employees' satisfaction with the company's resource management model and human resource strategic planning.

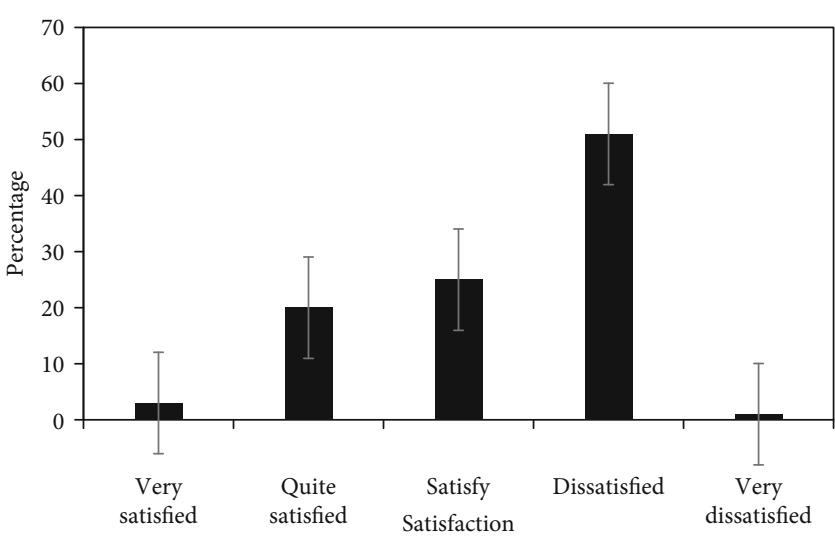

(a)

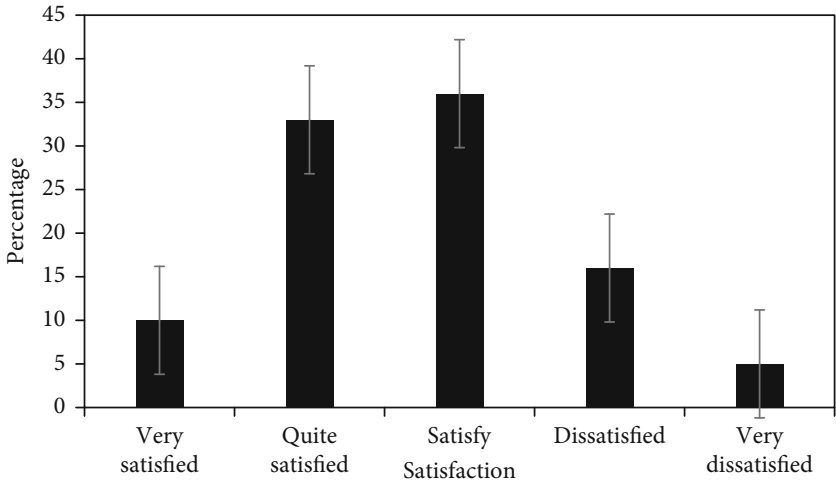

(b)

FIGURE 8: The rationality of the design of human resources evaluation indicators and the satisfaction of the fairness of the evaluation results of Huawei employees.

$79 \%$ of the total employees feel satisfied. Only $16 \%$ of employees were dissatisfied. We can find that Huawei's evaluation results are still relatively transparent. If the transparency of performance evaluation is increased on this basis, the results of performance evaluation will also have higher fairness. This can make the construction of the human resource management model more smooth and convenient. The satisfaction of Huawei employees with respect to the reasonableness of human resources compensation design and bonus distribution is shown in Table 3 .

It can be seen from Table 3 that most employees are quite satisfied with Huawei's HR compensation design. Among them, 23\% are very satisfied, 20\% are more satisfied, and $36 \%$ are satisfied, so overall, $79 \%$ of people are satisfied with Huawei. The current salary package is satisfactory, and only $11 \%$ are dissatisfied. Employees believe that Huawei's salary design is highly adaptable to today's society, and the salary package is relatively high. Therefore, employees are satisfied with the rationality of the current salary design. There are many people who are satisfied and dissatisfied with the rationality of the company's bonus distribution. Overall, 53\% are satisfied, and $47 \%$ are dissatisfied.
Employees believe that Huawei bonus distribution includes employee bonuses of the same job and the same level. The generally high level makes it difficult for bonuses to stimulate the enthusiasm of employees. At the same time, the department's implementation bonus is linked to the department's income level. Employees' satisfaction with the spiritual motivation and training opportunities of Huawei's human resources is shown in Table 4.

It can be seen from Table 4 that $23 \%$ of employees are quite satisfied with Huawei's spirit, $12 \%$ are very satisfied, and $33 \%$ are satisfied. However, a relatively large number of employees are dissatisfied with spiritual rewards. $32 \%$ of employees hold this view. It can be seen that employees believe that Huawei's spiritual incentives are not in place, that Huawei's culture is too wolfish and the pressure is relatively high, which makes employees I am dissatisfied with Huawei's spiritual motivation; most employees are satisfied with the training opportunities provided by Huawei, and only $4 \%$ are dissatisfied. Spiritual rewards are also called "honorary rewards." Reward measures that affirm, encourage, and promote the performance and achievements of civil servants by way of awarding honours. Synthesize the 
TABLE 3: Huawei employees' satisfaction with the reasonableness of human resources compensation design and bonus distribution.

\begin{tabular}{lccccc}
\hline Category & Very satisfied & More satisfied & Satisfy & Dissatisfied & Very dissatisfied \\
\hline Salary design & 23 & 20 & 36 & 11 & 10 \\
Bonus distribution & 3 & 20 & 30 & 45 & 2 \\
\hline
\end{tabular}

TABLE 4: Employees' satisfaction with the spiritual motivation and training opportunities of Huawei's human resources.

\begin{tabular}{lccccc}
\hline Category & Very satisfied & More satisfied & Satisfy & Dissatisfied & Very dissatisfied \\
\hline Mental stimulation & 12 & 23 & 33 & 22 & 10 \\
Training opportunity & 23 & 60 & 13 & 4 & 0 \\
\hline
\end{tabular}

spiritual rewards given to civil servants from all over the world, and the types mainly include verbal praise and verbal awards. Promotion rewards are reward measures that affirm, encourage, and promote the performance and achievements of civil servants by improving the rank of civil servants. It has the dual nature of spiritual rewards and material rewards. Among all the reward forms, the promotion reward has the highest level, and the incentive effect is also the strongest. This proves that the promotion platform that Huawei provides to employees is still very large, and it allows opportunities for employees to continue to learn and progress in the company.

\subsection{Enlightenment of Huawei's Human Resource} Management Model to the Development of $\mathrm{Hr}$ in Chinese Enterprises. People-oriented is the core of Huawei's human resource management. Ren Zhengfei said "Huawei regards employees as the company's first asset. For Huawei, business and capital are not the most important. Business can be expanded and replaced, capital can be held and converted, but talents are irreplaceable. Huawei builds and developed the Shared Service Center (SSC) to become a comprehensive delivery center to provide employees with more human resource services and customer-to-customer delivery, while also increasing the value of human resource management." The collaborative relationship between Huawei's three pillars of HR is shown in Figure 9.

Huawei has realized the process combination of the three pillars and functional modules to solve the relationship between the three pillars and modules. In traditional personnel management, modules are selected, trained, used, and stored. Specifically, it includes employee performance modules, job analysis, recruitment, training and development, organizational development, performance management, compensation and benefits, employee relations, and retirement management. Compared with the three-pillar model, traditional human resources pay more attention to human resource management and process results and pay more attention to intelligent management systems. Emphasizing the results does not mean that the human resource management function is transformed into a three-pillar model, but human resources are regarded as a key function and tool to improve the human resource management function. The times are constantly changing, and the environment is constantly changing. This fact has led to the company's need to keep pace with the times. In this context, when employee management changes, we can only survive, grow, and create greater value when we actively seek reforms and boldly transform to promote changes. For the upgrade direction and trend of Huawei's three-pillar HR model, we can propose the pattern shown in Figure 10.

The domestic company's three-pillar HR model has already digested and absorbed the practice and exploration of the emerging theory of the three-pillar HR in the early stage. Through innovation, it has been upgraded to the development and evolution characteristics of the second stage of the three-pillar HR. Represented by the model, the main path and trend direction of this upgrade are shown in Figure 11.

It can be seen from Figure 11 that from the above upgrade trend, four changes can be seen. First, expand a new perspective. The initial three-pillar human resource model only emphasized the three human resource support structures from the perspective of the organization, and Chinese companies not only emphasized the three pillars of human resources from the perspective of the organization's internal human resources but also from the perspective of the people and the environment. Interactions and talents between technology and organizational changes; second, platform supports upgrade from SSC to SDC. The traditional SSC just concentrates all administrative work related to human resources in a business unit of an enterprise group and establishes a service center; third, the service target is clear; fourth, it enriches the cultural connotation.

\section{Discussions}

The concept of human resource management originated from the first scientific management experience in the industrial age. Human resources have been developing rapidly and making innovations that keep pace with the times. Traditional human resource management theory divides human resource functions into six modules: human resource planning, recruitment and allocation, training and development, performance management, salary and benefits management, and employee relationship management. Huawei was born and grew up in China. Technology companies are developing rapidly and successfully. Their success is inseparable from good human resource management methods. The analysis and research of Huawei's human 


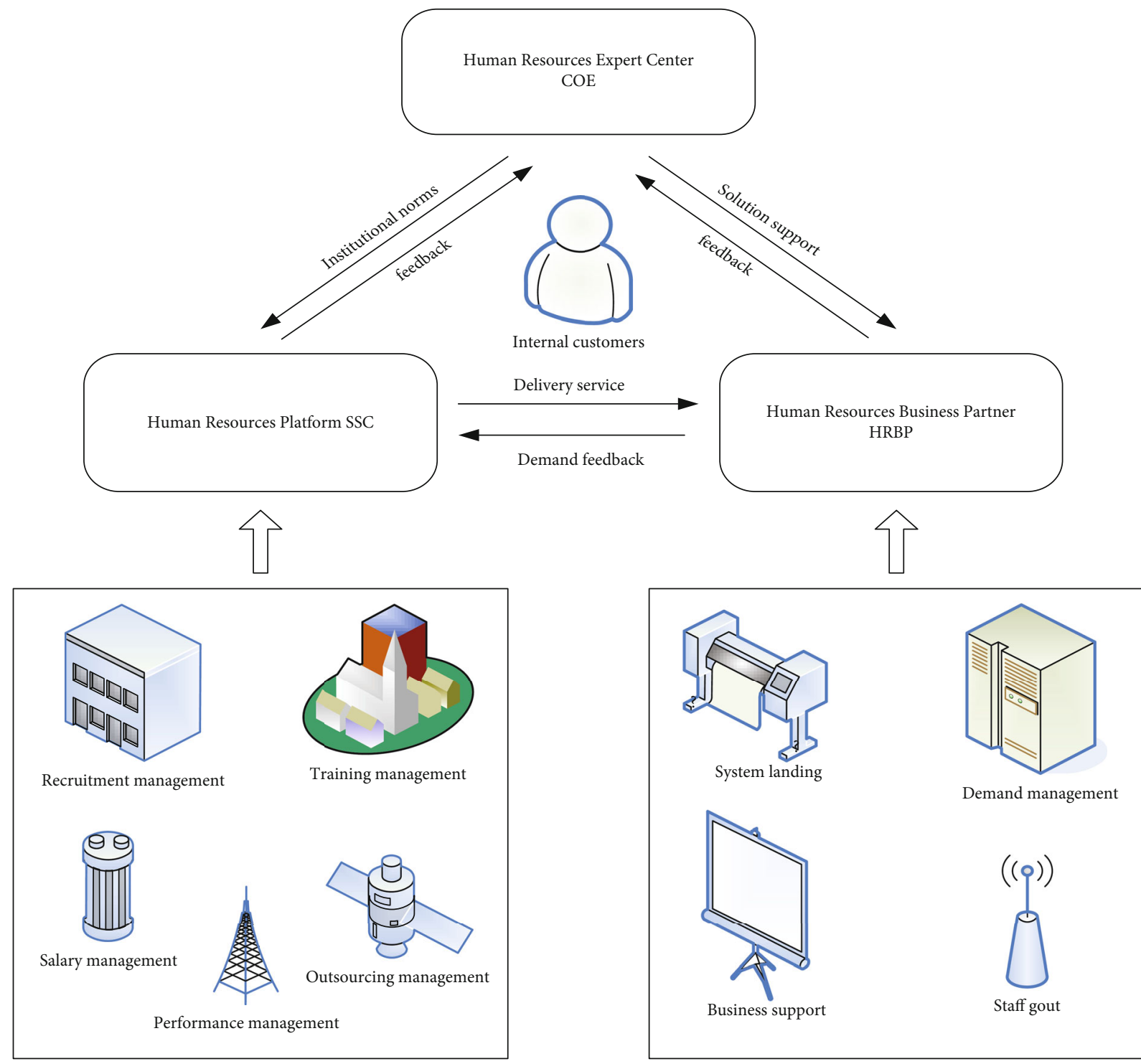

FIgURE 9: Huawei HR three-pillar collaboration diagram.

resource model based on wireless network communication and association rule algorithms show that

(1) The multiservice call admission control and association rule algorithm of the wireless cellular communication system is one of the very important wireless resource management algorithms. For multiservice applications, because it requires more radio resources than a simple voice service, accepting a newly arrived initial or handover-arriving multiservice call has a greater impact on existing calls. The functions of wireless resource management are all based on the allocation and adjustment of wireless resources. It can be seen that when the average speed is between $10 \mathrm{mps}$ and $20 \mathrm{mps}$, the overall trend is rising. However, the probability of interruption will oscillate very severely. Finally, when the mobility is very high to high mobility, that is, when it exceeds $20 \mathrm{mps}$, the probability of interruption will gradually maintain a stable state through a very slight increase. The price is lower BUR

(2) Starting from the current background of Huawei's human resource management, we analyzed the main background information of the development of Huawei's human resource management model. It can be found that Huawei employees are highly satisfied with the current situation of the company. They believe that Huawei's salary package is relatively high, the assessment results are relatively fair and transparent, and the company's platform is still very large. There are opportunities for employees to continue to learn and improve in the company.. However, the company's human resource management lacks the unity and coordination with Huawei's strategy, the promotion of new employees is slow, and the design of evaluation indicators is not reasonable 


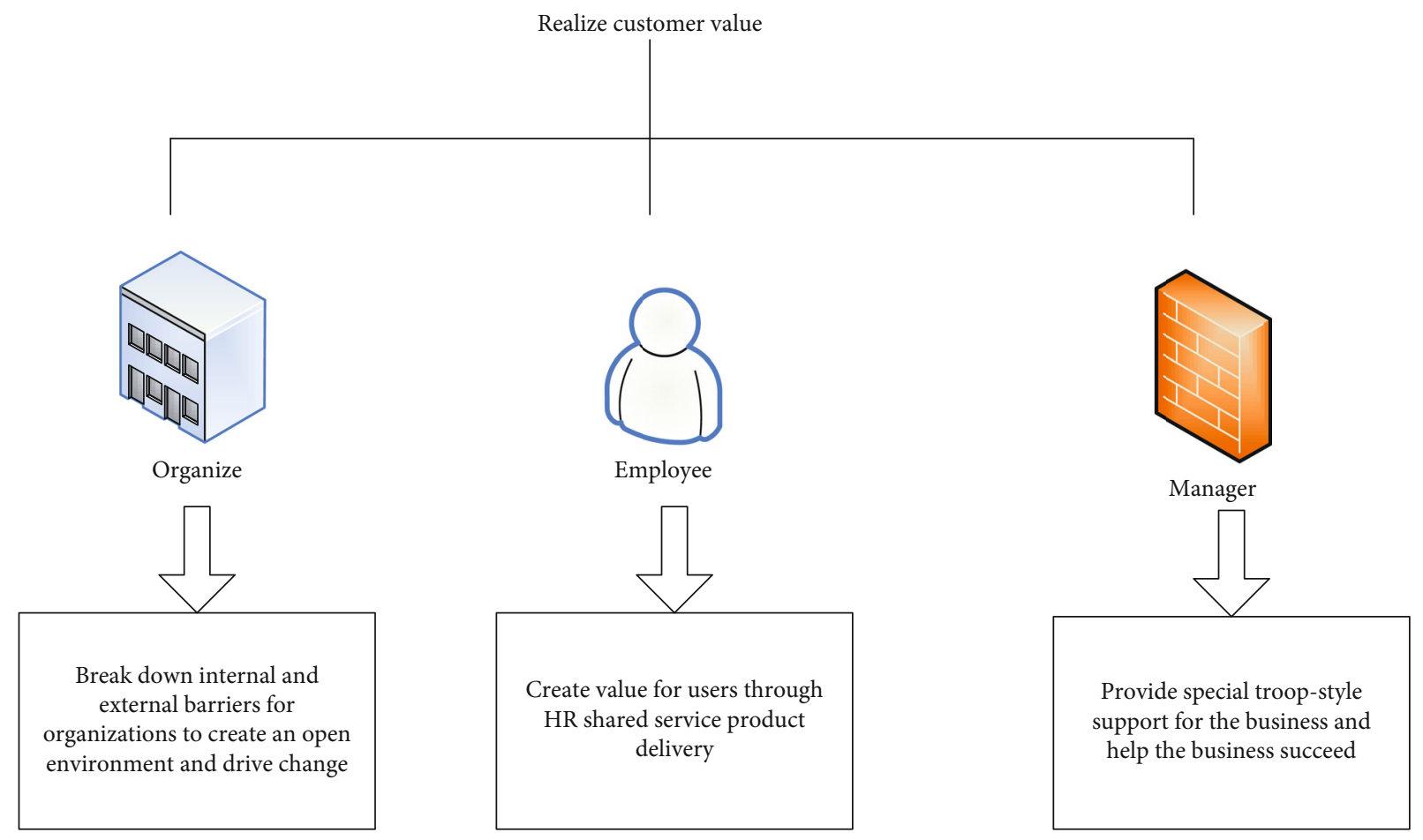

FIgURE 10: The three-pillar HR model of Chinese companies.

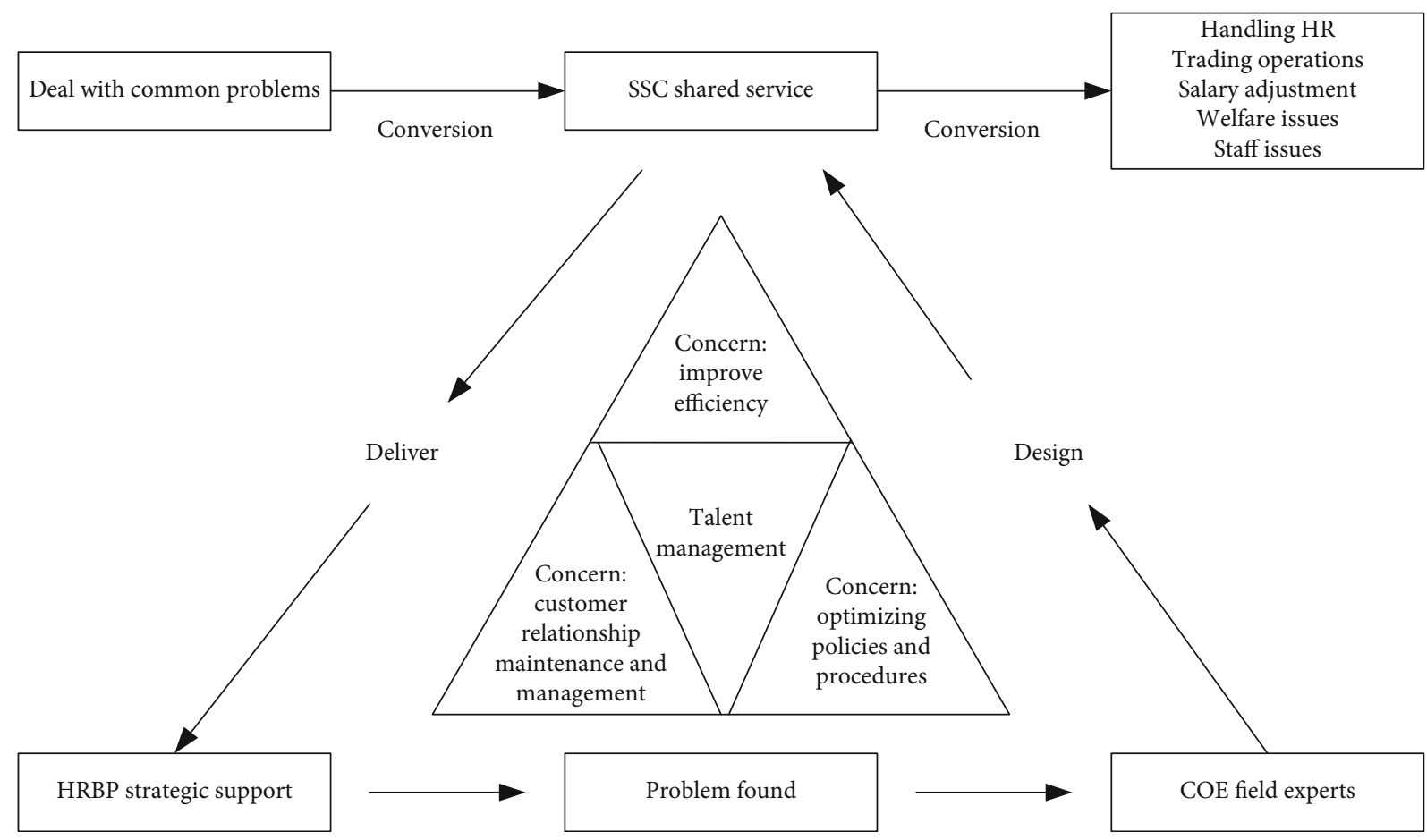

FIGURE 11: Upgrading of the three-pillar HR model of Chinese companies.

(3) As a new trend in human resource management, the HR three-pillar management model has a certain theoretical research foundation in China, but the application of Chinese enterprises has not been popularized, and the effect is not ideal. Huawei's threepillar HR practice: a growth-oriented HR strategy, all SDC based on user value, and the three guiding principles of not letting the three HR pillars become three ivory towers. The reasons for the successful practice of the three pillars of HR at Huawei are first, $\mathrm{COE}$ focuses on talented soldiers and organizational vitality; second, HRBP drives organizational changes 
and enhances organizational vitality; third, Huawei's three-dimensional upgrade from SSC to SDC

\section{Conclusions}

We take Huawei's human resource management model as the research object and use wireless network communication and association rule algorithms to study Huawei's human resource management model. It can be seen that Huawei has better remuneration packages and relatively fair assessment results and capability improvement platforms. Therefore, most employees agree with the status quo of Huawei's human resource model. However, Huawei also needs to unify and coordinate human resource management and Huawei's strategy, and the design of evaluation indicators needs to be more reasonable. The reason why Huawei's human resource management model can stand out in China is mainly because a COE focuses on elite soldiers and organizational vitality, and HRBP drives organizational changes and enhances organizational vitality; the three-dimensional upgrade from SSC to SDC results. In this paper, there are also shortcomings, mainly to conduct a comprehensive and in-depth analysis to explore whether the future direction of development or the development of the human resource management is obviously not in place. Therefore, in a further study, we should focus on the depth of research, making the paper more worthy of scrutiny.

\section{Data Availability}

No data were used to support this study.

\section{Conflicts of Interest}

The author states that this article has no conflict of interest.

\section{Acknowledgments}

This work was supported by Social Science Foundation of Shandong Province under grant 19CDSJ07, Social Science Foundation of Shandong Province under grant 19CDNJ19, and Key Subjects of Art Science in Shandong Province under grant CT201911167.

\section{References}

[1] M. Bastan, H. Shakouri Ganjavi, and R. Tavakkoli-Moghaddam, "Educational demographics: a system dynamics model for human resource management," International Journal of System Assurance Engineering and Management, vol. 11, no. 3, pp. 662-676, 2020.

[2] L. Galloway, N. Kamenou Aigbekaen, and S. Banu, "A relational approach to exploring inequalities within the human resource management model in the Middle East," International Journal of Work Organisation and Emotion, vol. 10, no. 3, pp. 216-223, 2019.

[3] H. Ludiya, M. Thlawur, A. M. Galtimari, and L. Hadiza, "Application of human resource management model of Fombrun, Devanna and Tichy (1984) on the performance of secondary school teachers in Maiduguri Metropolis, Borno State
Nigeria," International Journal of Scientific and Research Publications (IJSRP), vol. 9, no. 12, pp. 9615-9663, 2019.

[4] G. Wei and Y. Jin, "Human resource management model based on three-layer BP neural network and machine learning," Journal of Intelligent and Fuzzy Systems, vol. 40, no. 2, pp. 2289-2300, 2021.

[5] C. Gao and H. Sun, "Strategic transformation of human resource management model of ocean engineering: an exploratory study," Journal of Coastal Research, vol. 106, no. sp1, pp. 117-136, 2020.

[6] S. Ghasemi, A. Shahin, and A. Safari, "Proposing an improved economic value model for human resource valuation," International Journal of Productivity and Performance Management, vol. 67, no. 9, pp. 2108-2125, 2018.

[7] J. Mendy and M. Rahman, "Application of human resource management's universal model: an examination of people versus institutions as barriers of internationalization for SMEs in a small developing country," Thunderbird International Business Review, vol. 61, no. 2, pp. 363-374, 2019.

[8] Y. Li, D. Zhao, and S. Yan, "Research on travel agency human resource crisis early warning model based on BP neural network and computer software," Journal of Physics: Conference Series, vol. 1744, no. 4, pp. 420-461, 2021.

[9] D. Dahlan and F. Fatmawada, "The fusion of competence and integrity problems in transformation of public human resources management model," Jurnal Ilmiah Ilmu Administrasi Publik, vol. 9, no. 2, pp. 185-194, 2020.

[10] Q. Li, Y. Zhang, H. Kang, Y. Xin, and C. Shi, "Mining association rules between stroke risk factors based on the Apriori algorithm," Technology and Health Care, vol. 25, no. 1, pp. 197-205, 2017.

[11] B. Sowkarthika, A. Tiwari, and U. Pratap, "Elephant herding optimization based vague association rule mining algorithm," International Journal of Computer Applications, vol. 164, no. 5, pp. 15-23, 2017.

[12] L. H. Son, F. Chiclana, R. Kumar et al., "ARM-AMO: an efficient association rule mining algorithm based on animal migration optimization," Knowledge-Based Systems, vol. 154, no. 15 , pp. $68-80,2018$.

[13] M. Kabir, S. Xu, B. H. Kang, and Z. Zhao, “A new multiple seeds based genetic algorithm for discovering a set of interesting Boolean association rules," Expert Systems with Applications, vol. 74, no. 7, pp. 55-69, 2017.

[14] M. Rahaim and T. Little, "Interference in IM/DD optical wireless communication networks," IEEE/OSA Journal of Optical Communications and Networking, vol. 9, no. 9, pp. D51D63, 2017.

[15] H. Zhang, P. Dong, S. Yu, and J. Song, "A scalable and smart hierarchical wireless communication architecture based on network/user separation," IEEE Wireless Communications, vol. 24, no. 1, pp. 18-24, 2017.

[16] M. K. Dong and P. Popovski, "Reliable uplink communication through double association in wireless heterogeneous networks," IEEE Wireless Communications Letters, vol. 5, no. 3, pp. 312-315, 2017.

[17] K. Chi, Y. H. Zhu, Y. Li, L. Huang, and M. Xia, "Minimization of transmission completion time in wireless powered communication networks," IEEE Internet of Things Journal, vol. 4, no. 5, pp. 1671-1683, 2017.

[18] L. Zhu, F. R. Yu, T. Tang, and B. Ning, "Handoff performance improvements in an integrated train-ground communication 
system based on wireless network virtualization," IEEE Transactions on Intelligent Transportation Systems, vol. 18, no. 5, pp. 1165-1178, 2017.

[19] T. S. Rappaport, Y. Xing, G. R. MacCartney, A. F. Molisch, E. Mellios, and J. Zhang, "Overview of millimeter wave communications for fifth-generation (5G) wireless networks-with a focus on propagation models," IEEE Transactions on Antennas \& Propagation, vol. 65, no. 12, pp. 6213-6230, 2017.

[20] S. M. Kim, S. Ishida, S. Wang, and T. He, "Free side-channel cross-technology communication in wireless networks," IEEE/ACM Transactions on Networking, vol. 25, no. 5, pp. 2974-2987, 2017.

[21] P. Zhang, C. Wang, G. S. Aujla, N. Kumar, and M. Guizani, "IoV scenario: implementation of a bandwidth aware algorithm in wireless network communication mode," IEEE Transactions on Vehicular Technology, vol. 69, no. 12, pp. 15774$15785,2020$.

[22] J. Yang, Q. Yang, K. S. Kwak, and R. R. Rao, "Power-delay tradeoff in wireless powered communication networks," IEEE Transactions on Vehicular Technology, vol. 66, no. 4, pp. 3280-3292, 2017.

[23] D. du, B. Qi, M. Fei, and Z. Wang, "Quantized control of distributed event-triggered networked control systems with hybrid wired-wireless networks communication constraints," Information Sciences, vol. 380, no. 3, pp. 74-91, 2017.

[24] Q. Wu, Z. Yong, and Z. Rui, "Joint trajectory and communication design for multi-UAV enabled wireless networks," IEEE Transactions on Wireless Communications, vol. 17, 2017.

[25] H. Ju and R. Zhang, "User cooperation in wireless powered communication networks," IEEE Access, vol. 12, no. 8, pp. 36-46, 2017. 